\title{
Palakesi obiugri mütoloogiast III
}

\author{
Aado Lintrop
}

Üks Munkácsi kogutud Maailmavaatava Mehe sündi kujutav mütoloogiline laul algab kirjeldusega, kuidas Numi-Toorem oma naisega tülitses. Numi-Toorem tõstis mõõga, et naist lüüa. Nende vanim poeg takistas teda. Numi-Toorem vihastas ning sõnus oma naise alumisele maale. Naine laskus alumisele maale ning salaja tuli ilmale ta väike kuldsete käte, kuldsete jalgadega laps.

Kas kasvatas ta teda pikka või lühikest aega,
ennäe - ta sai väljasjooksmise ealiseks.
Äkki tema ringijooksmise ajal
küla tanumal häll seal seisab,
Pjopõr-hõbedast, kam-hõbedast häll seal seisab.
Poiss ronis sellesse mängima.
Ta isa Numi-Toorem tõmbas ta järsu ropsuga üles.

(Vogul Folklore: 18.)

Ent samast allikast pärinev muistend esitab asja hoopis teisiti:

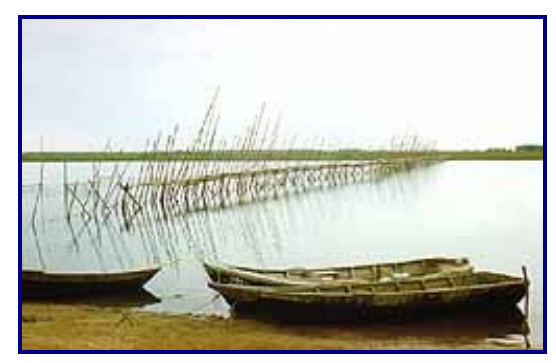

Kalatõke Kunovatil. Foto A. Lintrop 1989.

"Nende isa Numi-Kwores lasi kolm meest kahe taeva, kahe ilma vahele, neljas oli nende õde. Vanim mees neist on Numi-Toorem, teine mees on Sahl-Toorem, kõige väiksem mees on Tapel-ooika, Kaltesh-eekva on nende õde. Kõige vanem vend, vanim mees, võttis vene naise. Ükskord märkas ta, et ta naine on vahekorras allilma mehe Kul'-ooteriga. Ta haaras naisel juustest kinni ja virutas ta kolm korda vastu maa palet, siis viskas ta naise alla august, millest harilikult tavatses alla vaadata. Edasi polnud tal naisega mingit tegemist.

Ükskord ta õde Kaltesh-eekva kuulas, mis all toimub - ta kuulis ju last nutmas. "Kus ta nutab?" Ta läks ja vaatas allavaatamise august alla. Ennäe - ta vennanaine oli kukkunud Obi kaldale, ta oli murdnud parema kaenla all kaks ribi. Väike kuldsete käte ja jalgadega laps oli sündinud. Kaltesheekva süda hakkas kuldsete käte ja jalgadega lapse pärast väga valutama, ennäe - ta laskus alla. Ta tuli alla, selle maa peale, ta kasvatas ta üles. Sellest Kalteshi poolt üles kasvatatud väikesest naise pojast sai Maailmavaatav Mees. Kuni tänase päevani püsib maa tema väe läbi; venelane ja ugrilane kummardavad teda pühas majas ühtmoodi. Temast on palju jutte, temast on palju laule; terves maailmas pole ühtki tiivulist jumalust, pole ühtki jalalist jumalust, kes teda alandaks. Oma kätega hoiab ta paigal üleval liikuvat tiivulist jumalat, hoiab väikest tiivulist vaimu. Kui ta hakkab liikuma, hakkab olemasolev püha maa liikuma kogu oma suuruses. Sellepärast räägitaksegi temast jutte, sellepärast lauldaksegi temast laule." (Vogul Folklore: 17.)

Nagu näeme, on Kaltesh ühel juhul taevajumala naine ja Naise Poja ema, teisel juhul üks taevajumala lastest ja tema tädi. Mõlemas variandis on lapse taevase päritolu märgiks kuldsed käed ja jalad. Muistendis rõhutatakse, et Maailmavaatavat Meest kummardavad ühtviisi nii venelased kui ka ugrilased. Nagu ühest allpool esitatavast tekstist selgub, peetakse ühise jumaluse all silmas püha Nikolaust. Et side venelastega oleks veelgi selgem, figureerib Maailmavaatava Mehe emana vene naine.

Taevasele päritolule vaatamata esineb mitmetes mansi muistendites ja müütilistes lauludes Naise Poja kannatamise motiiv: 


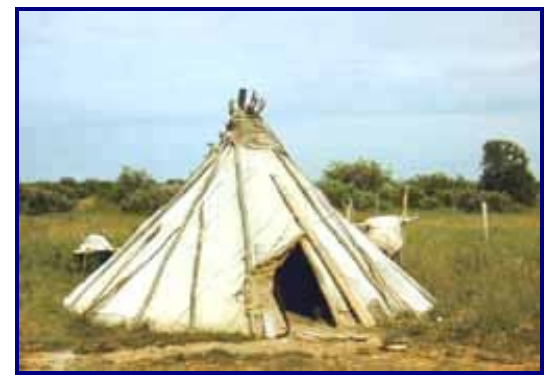

Püstkoda Lophari suvekülas.

Foto A. Lintrop 1989.

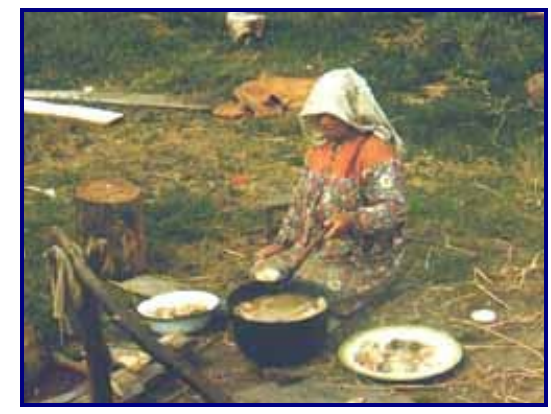

Handi naine keedetud kala taldrikusse tõstmas. Foto A. Lintrop 1989.
Isa pojake, isa kallis, ema pojake, ema kallis -

pikajuukseline vene mees, nende sõber, viis ta ära.

Ennäe - nad jõudsid ta sõbra majja, nad hoidsid last ukse kõrval nurgas,

ta sõber valas solki

talle kaela.

(Vogul Folklore: 21.)

.. nüüd viidi ta ära nugisenahkades samojeedist sõbra poolt.

Kas rändasid nad pikka või lühikest aega, nad jõudsid külla.

Nüüd viskasid nad kolmekümne sülla pikkusest raudköiest silmuse ümber lapse kaela, nad tõukasid ta saanist maha, sidudes kolmekümne sülla pikkuse raudse silmuse otsa saani jalase külge. Ühel pool teed, teisel pool teed kolmekümne sülla pikkuse raudse silmuse otsas tähnilise rabapüü tublit visklemist kuidas ta viskleb ja pöörleb!

Külalapsed naeravad:

"Ennäe, meie armas peremees on toonud kolmandaks talviseks ohvritoomiseks tõotatud kahe aasta vanuse põdrapullikese!"

(Samas: 21-22.)

"Ta võttis mammutiluu, millega rõivastelt lund kraabitakse, millega rõivaid klopitakse, ta peksis lapse peaaegu surnuks ja viskas ta küla prügihunnikusse." (Samas: 23.)

Võib-olla pidas K.F. Karjalainen silmas just neid tekste, kui väitis: "Eriti suure hulga ainest Mir susne humi elu ja tegevuse kujutamiseks on rahvaluulest kogunud ja korraldanud Munkácsi, kuid see tuleb meil siin suures osas kõrvale jätta, kuna see ei suuda kuigi palju valgustada rahvapärast ettekujutust." (Karjalainen 1918: 257.) Ometi on tegemist autentsete tekstidega. Olgu siinkohal võrdluseks toodud üks tänapäeval kogutud muistend:

"Kristus, vene jumal, tahtis kord näha, mis moodi tema lapsed elavad. Tuli taevast alla maa peale. Aga maa peal võtsid röövlid ta kinni, lõid risti külge ning viskasid prügimäele. Viskasid talle prügi peale ning läksid ise minema. Mõne aja pärast tuli põrsas õue. Läks prügihunniku juurde, tuhnib seal, korraga vaatab - nu, holera, vene jumala tapsid ära. Jooksis suure hirmuga ära. Ahah. No siis 
tuli tibu välja. Läks prügihunnikule, siblib seal, korraga näeb, Kristus lamab prügi all. Hakkas suure häälega kaagutama. Perenaine tuli välja, et mida see tibu kaagutab seal, vaatab - oh, vene jumal on tapetud! Kutsus kõik kokku. Võtsid Kristuse üles, pesid ta puhtaks ning panid kirikusse altari peale. Seal oli ta siis kolm päeva ning siis läks taevasse. Ahah."(Barkalaja 1996: 103-104).

Tsiteeritud laulus tõusis ka poolsurnuks pekstud Maailmavaatav Mees prügihunnikust, muutus äkki tihedat rõngassärki kandvaks sõdalaseks, tappis kõik need, kes teda olid mõnitanud ning muljus puruks nende linnad. Ta tappis ka onu, kes oli ta oma vene sõbrale kinkinud. Siis jõudis ta oma isa Numi-Tooremi majani. Isa küsis: "Kas sa tulid, mu pojake?" - "Ma tulin." (Vogul Folklore 24-25.) Võib-olla on Maailmavaatava Mehe kujutelmas shamanistlik väljavalitu kannatamise motiiv segunenud kristlikuga. Võib-olla saab Naise Poja nimeski näha sidet Inimese Pojaga.

Üks Munkácsi poolt avaldatud muistend sellest, kuidas Maailmavaatav Mees sai oma väe, on eriti huvitav:

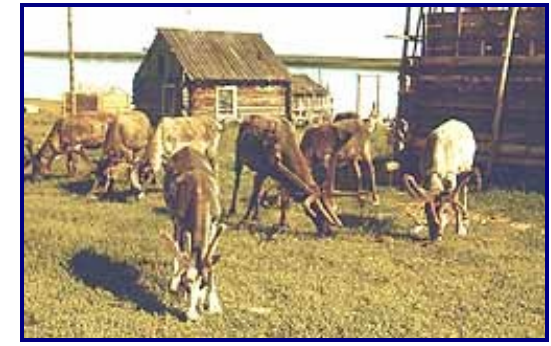

Põhjapõdrad Ust-Voikaris.

Foto A. Lintrop 1989.
"Meie isal Numi-Toorumil oli seitse meest. Ühe neist tahtis ta teha maailma vaatavaks. "Huvitav, kes meie seast saab Maailmavaatavaks Meheks?" küsisid nad üksteiselt. Kesk-Sosva taat ütles: "Mina saan!" Naise Pojakese onu Taapel-oika ütles Naise Pojakesele nii: "Poiss, hoia ennast minu ligi!" Seitse hobust jooksis. Taapel-oika ütles: "Kuulake mind! Las see mees, kelle kutsel need seitse hobust ta käte külge kinnituvad, saab Maailmavaatavaks Meheks." Nad panid oma käed valmis, et hobused saaksid tulla ja kinnituda, aga ükskõik kuidas nad ka kutsusid, kõik oli asjatu. Kui Naise Pojake kutsus, seisis seitse hobust kohe seal. "Kuulge," ütles ta onu, "tema on Maailmavaatav Mees!" Teised ütlesid: "Sellest ei piisa, tuleb võita võiduajamine. Las see meie seast, kelle käsi esimesena langeb Numi-Toorumi väravale, saab maailma vaatavaks." Siis hakkasid nad võidu sõitma. Hobuse seljas istuv mees ajas võidu hobusega sõites, põhjapõdra seljas istuv mees ajas võidu põhjapõdraga sõites. Ta onu rakendas kaks punast põdravasikat. Ta ütles Naise Pojakesele: "Pojake, mida sa võiduajamisel sõitmiseks tahaksid? Võta need mu kaks viletsat punast vasikat. Aja võidu nende teraste loomadega!" Naise Pojake mõtles: "Kuhu ma lähen nende viletsate loomadega? Sinna ma jäängi, kus ma nende selga istun." Ta onu ütles: "Pojake, ometi võib juhtuda, et kui sa seisad paigal, siis seisad sa paigal." Ennäe, Naise Pojake istus selga. Ühe hetkega tegid nad tiiru ümber selle ilma, ja kui nad jõudsid Toorumi maja väravani, langesid kõigi käed Naise Pojakese käe peale. Naise Pojake oli esimesena Toorumi majani jõudnud. "Sa oled Maailmavaatav Mees," ütlesid nad. "Loomulikult olen," ütles Naise Pojake.

Numi-Toorum ütles oma seitsmele mehele: "Sööge, mu kallid. Kas te töötate kaua või lühikest aega?" Ta lõikas tükkideks kolmnurkse paberitüki. "Kuulge," ütles ta, "see teie seast, kes saab metsa puuga, kuivanud puuga, rohelise puuga märgi oma pihku, see mees teie seast saab Maailmavaatavaks Meheks." Oma pihke avades sirutasid nad käed välja. "Vaadake siia!" - Kõik paberitükid olid tal peos. Kesk-Sosva taat sai üht sorti puuga, kuivanud puuga märgi oma pihku, teist sorti puud, rohelist puud seal polnud. Naise Pojakese paberitükil olid kogu maailmas leiduvad rohelised puud, kogu maailmas leiduvad kuivanud puud ära märgitud. "Ennäe, sa oled Maailmavaatav Mees!" ütlesid nad. "Seal, kus on venelased, seal, kus on vogulid, kunagi sa hakkad neid kõiki hoidma!"

Sel ajal, kui nad sõid, tõusis Maailmavaatav Mees äkki püsti. "Ennäe, kaks meest on surmasuus!" ütles ta. Teised vaatasid, küsisid: "Kus?" Naise Pojake ütles: "Vaadake, kui nad merel kala püüdsid, pööras tuul nad mere keskel kummuli, nad kahlavad vööni ulatuvas vees ringi, niimoodi on tuul neid puhunud. Ennäe, see on neid liivalaiule viinud." Kui nad vaatasid, ütlesid nad: "Miks see, mis sa näed, on kindlasti õige?" Nende isa ütles: "Ennäe, tema on Maailmavaatav Mees!" Siis andis ta 
talle väe. Tänase päevani kummardavad venelased ja vogulid teda." (Vogul Folklore: 25-26.)

Selles jutus on Maailmavaatav Mees otseselt seostatud püha Nikolausiga (Nikolai Imetegijaga), kes teatavasti oli ka meremeeste kaitsja. Siinkohal ei tohi jätta mainimata üht teadaolevat ajaloolist fakti -1600. aastal ehitati Obi-äärsete hantide Koda vürstiriigi keskusesse Elustava Kolmainsuse kirik, kus oli ka Nikolai Imetegija altar (Bahrushin 1955: 127). Võib-olla hakkas just sealt obiugrilaste seas levima Püha Nikolaiga seotud pärimus.

Allilma valitseja $K_{\boldsymbol{u}} \boldsymbol{l}^{\prime}$ ootõr. Artikli esimeses osas mainitud Munkácsi poolt kogutud müütiline laul, milles kirjeldatakse ta päritolu, on järgmine (kahjuks inglisekeelsest proosavariandist tõlgituna):

"Oma isa Numi-Tooremi kasvatusel muutusin üha lihaselisemaks, mu käsivarred muutusid üha tugevamaks. Ta hoidis mind seitsme raudlukuga majas. Ma liigutasin seitset kinnipandud lukku avanes nõelasilma suurune ava. Oma seitsme kuratliku riuka abil kasvasin (läbi ava) välja, sammusin ta (isa) tanumalise küla tanumal, mu parema jala saabas tuli jalast. Ma vaatasin alla - üks väike jalaline jumal esitas seal all seitset sorti osavaid jalalisi vägitükke, ta võttis kuulsat raha ja head ohvritoitu. Kui mu isa Numi-Toorem lubaks mul laskuda, võtaksin minagi samal kombel nimekat raha ja head ohvritoitu."

Isa tuli koju, Kolli-isand palus, et teda alla lubataks. Isa vastas:

"Kui tuleb kunagi aeg, mil luuakse inimene, kes hakkab oma elu elama, kuidas saan ma lasta alla inimesi söövat suuresilmalist kolli?" (Kolli-isand ütles): "Ei, isa, (kui) nad annavad mulle nimekat raha ja head ohvritoitu, (siis) mina pikendan inimese elupäevi." Numi-Toorem vihastas, võttis tal jalast kinni ja viskas ta alla. Kolli-isand kukkus toidurikka mere keskele. Ta ütles: "Kui mu laul läheb edasi, siis las tõuseb siia liivalaid, mis on nii suur, et sellel saab lamada!" Kerkiski nii suur liivalaid, et sellel sai lamada. Ta lamas seal seitse ööd ja seitse päeva. Ta tädi, hõbesuine kägu, laulis: "Homme, kui meie ema leegitsev päike tõuseb isa maja otsa, tõuseb mere alumise otsa poolt tuul - Toorem ujutab üle liivalaiu, mis on nii suur, et sellel saab lamada. Uju sinnapoole, kuhu tuul läheb."

Kolli-isand tegi õpetust mööda ja jõudis saarele. Ta jäi kõhuli lamama. Tädi hõbesuine kägu laulis:

"Kas kavatsed veel pikka või lühikest aega lamada? Tõuse üles! Viska üle pea mõned kuuse küljest kistud laastud! Siis tekib sinna nelinurkne palktare. Jaluta sellel Obi saarel ringi! Otsi oma paremast taskust, sa leiad seitse ühe sõrmuse peale lükitud hõbetükki, viska need seitse ühe sõrmuse peale lükitud hõbetükki minema - sellest sünnib seitse raudvibuga meest, sellest sünnib seitse raudnoolega meest, kerkib piirideta linn."

Maad mööda ringi käiv Kuulus Isand (1) vaatas maad mööda ringi käies alla - "Ilma meie loata on piiritu linn kerkinud." Ennäe, ta läks sisse, Kolli-isand võttis ta vastu. Ta ütles: "Väimees, kui sa tahad, siis istu nurgelise maja nurka." Kuulsal Isandal oli Kolli-isanda äiana häbi. Tal polnud tüdrukutele söögiks kõlblikku pulmatoitu, tal polnud poistele söögiks kõlblikku pulmatoitu. Väikese osava jumala seitsme vägitüki abil tõmbas ta omaenese linnast sinna oma seitsme uksesagaraga aida, seda nurgast haarates. Sealt tuli poistele söögiks kõlblik pulmatoit, sealt tuli tüdrukutele söögiks kõlblik pulmatoit. Nad sõid pulmatoitu, nad jõid pulmajooki. Kolli-isand elab praegugi koos äiaga ning saab elama ka tulevikus." (Vogul Folklore: 43-45.)

Samas väljaandes leidub teinegi tekst, kus Maailmavaatav Mees (Musta Soobli Nahast Kraega Isand) võitleb kõigepealt laiatiivaliste tiivuliste loomadega, seejärel eksleb mingi jõe kaldal, kus kohtab Kolli-isanda tütart, kellega ta elama hakkab. Kolli-isand on see, kes käsib tal tiivulise hobuse selga istuda, ilmselt lootes, et väimees ei suuda sadulas püsida ja kukub surnuks. Ent Maailmavaatav Mees talitab naise nõuande kohaselt ja jääb hobuse selga püsima. (Samas 27-29.) Artikli algul ära toodud muistendis, kus taevajumala vanim poeg süüdistas oma naist abielurikkumises, 
võis $K u l^{\prime}$ olla koguni Maailmavaatava Mehe isa. Paaris Steinitzi poolt publitseeritud handi muistendites, kus Püha Linna Taat esineb Kaltash-imi venna ja Maailmavaatava Mehe onuna, on Maailmavaatava Mehe isaks Seitsme Soobli Kõrgune Isand. Tekstist selgub, et ta linn asub Obi ääres ning et teel Seitsme/Kuue Kivisilmse Isanda juurde ja tagasi möödub kangelane ka onu linnast. Artiklis "Väike mos'-naine. Ühe (muinas)jutu lugu" mõistatasin, kes võiks olla nii handi kui ka mansi muistendites esinev Seitsme Soobli Kõrgune Isand. Siis seostasin teda Toorumiga, ent praegu tundub, et tegemist võib olla ka allilma valitsejaga.

Kul'i maapeale laskmise lugu sarnaneb suuresti karu sünnilooga, esineb isegi jala läbi taevapõranda vajumise motiiv, kuid karu kohtleb Numi-Toorum paremini kui oma naist ja Kolli-isandat. Kuigi karu lõhub isa keelust hoolimata lukud ja pääseb toast välja, ei viska taevajumal teda koju tulles maa peale, vaid laseb ta hällis alla alles pärast pikka lunimist.

Steinitzi poolt kogutud karupeielaulude hulgas on ka "Väikeseid Tüdrukuid Neelava Valitseja laul", mille kangelane, tumedaveelise püha mere peal elav valitseja on kahtlemata Kolli-isand, kes elab musta looma küllases pesas, punase looma küllases pesas. Tema sõidab karupeietele niimoodi:

kasetohust külgedega seitsmesse paati, kasetohust külgedega kuude paati mina, isand, istun.

Obi-äärsest seitsmest linnast,

Obi-äärsest kuuest linnast väikesi poisse, väikesi tüdrukuid neelata võttes mina, isand, (läbi) lähen.

(Steinitz 1939: 381.)

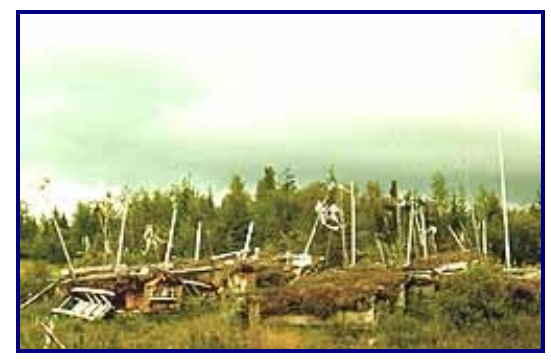

Handi surnuaed. Foto A. Lintrop 1989.

Kuigi on tegemist allilma valitsejaga, tõotab temagi teiste jumaluste kombel pidumajas viibijatele jahi- ja kalaõnne ning kaitset haiguste vastu:
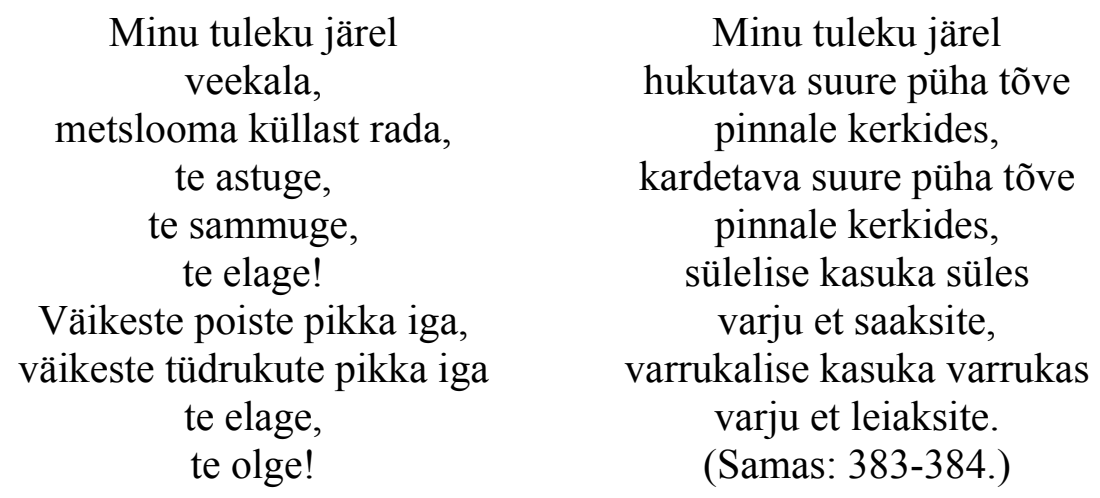

Püha Linna Taat - mansi Jalp uus ooika, handi Jem vosh iki. Tema elupaigaks on Püha Linn, mis komikeelsel kujul Vezhakarõ on kantud ka ametlike külanimede hulka. Linna haldja antropomorfseks esinemiskujuks on relvis sõdalane, zoomorfseks aga karu. Sellest tuleneb ka üks tema nimesid - Küüneline Valitseja (Schmidt 1989: 212-215). Steinitzi poolt handi karupeielaulude hulgas üles kirjutatud Püha Linna Taadi kutsumislaul algab nii:

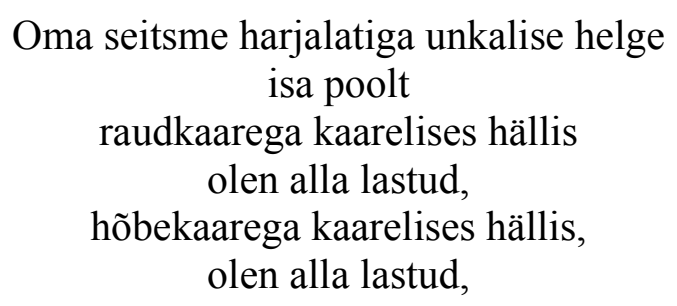


raudketi kallis otsas,

vaskketi kallis otsas

olen alla lastud,

Sooloomaküüneline Valitseja,

Metsloomaküüneline Valitseja,

mina, isand, olen alla lastud.

(Steinitz 1939: 384-385.)

Püha Linna Taadi elupaigaks on jooksva hobuse kujuline linn/sammuva hobuse kujuline linn (samas: 385; 403), mansi lauludes ka lehelooma kujuline linn/liblelooma kujuline linn:

Lehelooma kujulise linna,

liblelooma kujulise linna,

jooksva hobuse (kujulise) lahtiharutatud linna,

sammuva hobuse (kujulise) lahtiharutatud linna keskel ma istun.

Seitsme karvasilmse metsavaimu hulka,

kuue karvasilmse isanda hulka

Numi-Toorum, mu isa, on mind sõnunud

soolooma, metslooma kahel kujul.

(Kannisto, Liimola 1951: 349-350.)

Tsiteeritud handi kutsumislaulus kirjeldatakse Püha Linna Taadi teekonda oma elupaigast pidumajja järgmiste sõnadega:

\author{
Soolooma püha kuju \\ ma endale võtan, \\ metslooma püha kuju \\ ma endale võtan. \\ maa külmumise seitsmes lõhes, \\ maa külmumise kuues lõhes \\ ma käpuli käin. \\ Kõmava heli, \\ raksuva heli saatel \\ kaugelt langenud vihmahoo kombel, \\ kaugelt langenud tuulehoo kombel \\ ma langen \\ ühe põdrapulli jooksmise suurusele seljandikule.
}

(Steinitz 1939: 387-388.)

Karupeietel on teda esitatud valges kitlis mehena, kellel on rätt kaelas ja kummaski käes nool. Nool on pistetud ka läbi ta peakatte kuklaosa (Tshernetsov 1974: 314). Nagu juba mainitud, külastab Obi-äärsete hantide uskumuste põhjal surija hing enne allilma lahkumist viimasena just tema elupaika. Handi karupeiete etenduslaulus pöördub surnu kõigepealt Maailmavaatava Mehe, seejärel Kaltash-imi poole, paludes päästmist:

Oma väikesi luid kui ma raputan, väikeste loomade poolt need ära kantakse, oma suuri luid kui ma raputan, suurte loomade poolt need ära kantakse.

Pärast seda nüüd

sooblisuuruse pehme palve

kuhu laotan, 
karusloomasuuruse pehme palve

kuhu laotan?

(Samas: 400-401.)

Viimaks kutsub ta appi Püha Linna Taati:

Jooksva hobuse kujuline linn, sammuva hobuse kujuline linn, sooblisuuruse pehme palve sinule laotan,

karusloomasuuruse pehme palve sinule laotan.

Sooloomakujuline Valitseja, Metsloomakujuline Valitseja, sülesügavusest sinirebaseaugust, põlvesügavusest sinirebaseaugust, kui sa mind välja võtad, ühe köiega seotud seitse musta, ühe köiega seotud kuus musta sulle ohverdan. Pärast seda nüüd Sooloomakujuline Valitseja, Metsloomakujuline Valitseja, kaugelt langeva vihmahoo kombel et sa siia langeksid, kaugelt langeva tuulehoo kombel et sa siia langeksid.(2)

(Samas: 403-404.)

Kuna laul kannab pealkirja "Surnu elluäratamine", siis võib arvata, et Püha Linna Taat päästabki surnu hauast välja. Ilmselt etendati see etteaste osa pantomiimina.

Juba mainitud Steinitzi poolt publitseeritud handi muistendis esineb Püha Linna Taat Kaltash-imi venna ja Maailmavaatava Mehe onuna, kes oma õepoega igati aitab. Selles rollis langeb Püha Linna Taat kokku Taapal/Toopal ooikaga. Võib-olla ongi Taapal ooika üks Püha linna taadi eufemistlikke nimesid mansidel, kuna nende suhtes paikneb ta elupaik Obi teisel kaldal. Kannisto on märkinud: "Uusõn ootõr ooika on Saveli järgi ka üks pupõg (kaitsevaim), kes elab aas ta paalt (sealpool Obi jõge) Berjozovost ülesvoolu, kohas nimega jalp uus (püha linn)." (Kannisto, Liimola 1956: 210.).

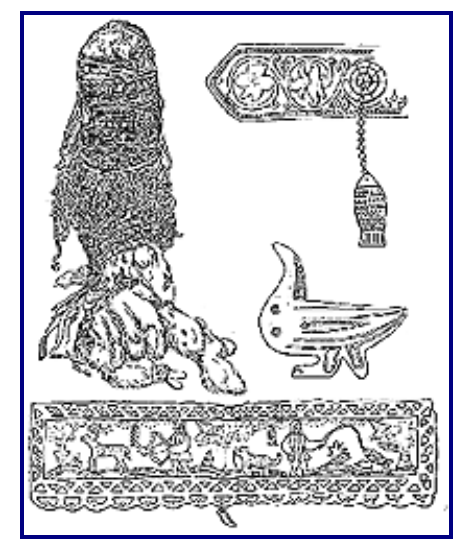

Kazõmi haldjatari kujutav nukk.

Kazõmi jõe haldjatar - Kassum-imi. Teda peeti Numi-Toorumi tütreks. Peamine talle pühendatud ohvripaik asub Juilski küla lähedal. Vanasti käisid seal lisaks Kazõmi-äärsetele hantidele ohverdamas ka Salehhardi, Kunovati, Obi ja Surguti handid. Tema pühapaik hävitati 1962. aastal kolhoosnike koosoleku otsuse põhjal. Kultuseaidas olnud kuld- ja hõberaha kadus jäljetult, haldjatari kujutis, nn. hõbenaine, sattus aga Hantõ-Mansiiski muuseumisse. See on traditsiooniline puust nukk, mis rõivastatud karusnahkade ja rättidega ning ehitud hõbedast ehisplaatidega. Jahistseene kujutavad plaadid on valmistatud Peterburgis 19. sajandi esimesel poolel. Üks nukku ehtinud veelinnu kujuline ripats pärineb aga esimesest aastatuhandest $\mathrm{p} \mathrm{Kr}$. Handi karupeielaulude hulgas on ka Kazõmi haldjatari kutsumislaul, mille algus kuulutab, et laulu kangelane on seitsme harjalatiga unkalise helge Toorumi poolt määratud (sõnutud) ning lastud kuldse kaarega hällis, kuldse keti kallis otsas järve kohale, mis on metsise puguna ümar, pardi puguna ümar, on lastud väikese kauri pesaga, suure kauri pesaga õotsuvale mättale. Huvi pakuvad laulu järgmised värsid:

Üht mu nime nimetatakse: Musta Kassi Kujuline Väike Haldjatar, Valge Kassi Kujuline Väike Haldjatar mu nime teatakse; Emasoobli Sisina Väike Haldjatar,

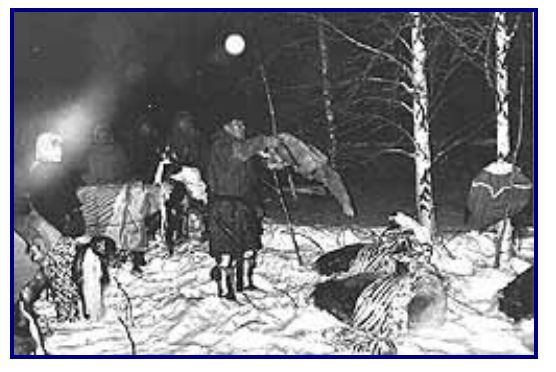

Ohverdamine Kazõmi haldjatarile Juilskis 1989. Foto A. Lintrop. 
Isasoobli Sisina Väike Haldjatar mu nime teatakse.

(Steinitz 1939: 366-367.)

Samas aga ei liigu Kazõmi haldjatar kassina. Pidumajja läheb ta hoopis nõnda:

$$
\begin{gathered}
\text { Ühest emast sündinud kaht aastast põtra } \\
\text { pole mul tarvis: } \\
\text { metshaldjatüdrukuna patsiline väike haldjatar, } \\
\text { metshaldjatüdruku kolm pikka sammu } \\
\text { mina, haldjatar, võtan, } \\
\text { metshaldjatüdruku neli pikka sammu } \\
\text { mina, haldjatar, võtan. }
\end{gathered}
$$

(Samas: 366.)

\section{Viidatud kirjandus:}

Bahrushin 1955 = Bahrushin S. V. Ostjatskie $i$ vogulskie knjazhestva v XVI-XVII vv. Nautshnõje trudõ III. Moskva.

Barkalaja 1996 = Barkalaja, A. Handi rahvausundist, selle seostest vene õigeusu ja teadusliku mõtlemisega. Väitekiri magistrikraadi taotlemiseks eesti rahvaluule alal. Tartu Ülikool.

Kannisto, Liimola 1951 = Kannisto, A., Liimola, M. Wogulische Volksdichtung I. Texte mytischen Inhalts. Suomalais-Ugrilaisen Seuran Toimituksia 101. Helsinki.

Kannisto, Liimola 1956 = Kannisto, A., Liimola, M. Wogulische Volksdichtung III. Märchen. Suomalais-Ugrilaisen Seuran Toimituksia 111. Helsinki.

Karjalainen 1918 = Karjalainen, K. F. Jugralaisten uskonto. Suomensuvun uskonnot III. Porvoo. Scmidt 1989 = Schmidt, É. Bear Cult and Mythology of the Northern Ob-Ugrians. Uralic Mythology and Folklore. Budapest, pp 187-232.

Vogul Folklore $=$ Vogul Folklore Collected by Bernt Munkácsi. Selected and edited by O. J. Sadovszky and M. Hoppl. Budapest 1995.

Steinitz 1939 = Steinitz, W. Ostjakische Volksdichtung und Erzählungen aus Zwei Dialekten. 1. Teil. Õpetatud Eesti Seltsi Toimetused XXXI. Tartu.

Tshernetsov $1974=$ Tshernetsov, V. T. Bärenfest bei den Ob-Ugriern. Acta Ethnographica Academiae Scientiarum Hungaricae, tomus XXIII, fasciculi 2-4, Budapest, pp. 285-319. 


\section{Maailmavaatav Mees}

2. Steinitzi poolt publitseeritud lauludes liigub (langeb) ainult Püha Linna Taat vihma- või tuulehoo kombel. Kannisto kogutud tekstide hulgas leidub Maailmavaatava Mehe poja (sulgudes lisatud Jovtimsoos ootõrpõg - Jovtimsoosi Isandapoeg) laul, milles read: kiiresti langev vihmapiisk,/ kiiresti siia ju lange,/ kiiresti langev tuulepiisk,/ kiiresti siia ju lange (Kannisto, Liimola 1951: 324, värsid 8-11). Maailmavaatava Mehe etenduslaulus aga on värsid: ülevalt langenud vihmapiisamees,/ ülevalt langenud tuulepiisa mees,/ siia et langeksid! (Kannisto, Liimola 1959: 38, värsid 36-38). 